\title{
Control and Management of Tomato Leafminer -Tuta Absoluta (Meyrick) (Lepidotera, Gelechiidae).A Review
}

\author{
Daniel Tsingay Illakwahhi, Prof. Bajarang Bali Lal Srivastava* \\ Chemistry Department, College of Natural and Mathematical Sciences, University of Dodoma, Tanzania.
}

\begin{abstract}
The tomato leafminer, Tuta absoluta (Meyrick), is becoming one of the key pests of tomato in Tanzania; which account for its production loss of up to 80 to $100 \%$ if left unchecked. The pest was first introduced in Tanzania in 2014.due to porous nature of our borders and lack of quarantine regulations implementation. Tomato producers in Tanzania have little understanding of leafminers, and hence lack best practices for it control. The pest have developed resistance to dozens of pesticides and therefore the (IPM) strategy that employs bio-chemical, biological, physical and cultural methods is the only best option we had at time. Since its introduction in 2014, there was no any sound action plan implemented. Thus, the aim of this review paper is to call for attentions and concerted actions of concerned sectors by describing the potential damage of the pest, its entry, pathways and its control methods. There is a need for all stakeholders to meet and discuss the possible ways of containing and controlling the current Tuta absoluta outbreak.
\end{abstract}

Key words: Integrated Pest Management (IPM), pest control, pheromone, tomato, Tuta absoluta

\section{Introduction}

In Tanzania, tomato (Lycopersicon esculentum Mill. or Solanum lycopersicum L) is one of the most important edible vegetable crops and used as source of income. Tomato produced by small and medium scale farmers for home consumption and as a source of income [1,2]. Recently, the production of tomato has been decreasing due to various factors including pest and disease [3,4]. Tomato production faces many problems from several causes such as seasonal weather, temperature, humidity, diseases and insect pests. There are several insect species feed on tomato [5] for examples: thrips, whitefly, tomato fruit worm, leafminer, leafhopper, aphid, mites and mealy bug. Introduction of non-indigenous species like tomato leaf miner Tuta absoluta to the new biotic community of the world has brought several problems in different places in the world. Among the newly introduced species in Tanzania that are of significant economic importance is Tuta absoluta[1-3]. Due to lack of natural barriers, porous borders and lack of quarantine regulation implementation, the wild species can move from one ecological community to the other through human activities. This invasive pest -Tuta absoluta commonly known as the Tomato leaf miner is considered a serious threat to tomato production worldwide [4]. Tuta absoluta can destroy an entire tomato farm, whether in the open field or in a greenhouse, if effective control measures are not employed. Thousands of tomato farmers in Tanzania are suffering from serious production losses due to devastating pest that destroyed their precious crop $[3,4,6]$.

The leafminers, T. absoluta, originate from South America[7],is a significant pest of tomato (Solanum lycopersicum L.), as well as other solanaceous crops like eggplants, peppers, potatoes, beans and datura[1,2]. It attacks all aerial parts of the host (leaves, stems and fruits) and feeds within the tissues [1].

The pest was reported for the first time in Tanzania in August 2014 and since then invaded different parts of the country [4]. The pest started infesting tomato farms in the northern part of the country to regions like Arusha, Manyara and Kilimanjaro. This pest can cause losses of up to $80-100 \%$ in tomato farms in both greenhouses and open field if control measures are not checked. Once introduced, T. absoluta can be spread by seedlings, infested vines with tomato fruit, tomato fruit and used containers. Outdoor markets, vegetable repacking and distribution centers are potential introduction points in the spread of this pest [2].

The use of chemical pesticides as its control measure is highly sought and the most effective method to reduce T. absoluta treat level. However, the need for alternative control methods is encouraged, considering that, the pest has developed resistance to dozens of the pesticides and the negative side effects of pesticides over-use to the environment and beneficial arthropods [1]. Control using sex- based pheromone to prevent mating has been developed; however, the ability of female $T$. absoluta to reproduce parthenogenetically weakened any of these pheromone-based controls [1, 8]. Some insects may be the best controlled by a combination of practices that are not fully effective when used alone; $T$. absoluta is one of them. To control those pests effectively, it is critical to combine all available control measures including cultural methods, biological control agents and the correct use of registered pesticides [9]. An Integrated Pest Management (IPM) strategy that employs bio-chemical, biological, physical and cultural methods is the only best option we had at time. According to [3], Tanzania farmers' had poor classification and low knowledge on Tuta absoluta and its control; what makes the matter more complicated. 
Since it was introduced in Tanzania in 2014, there was no any sound strategies and action plan being implemented by the government, research institutions or other horticultural stakeholders to control and halt the spread of $T$. absoluta to new areas; neither there were no programmes initiated to create farmers awareness on the threat levels of the pest and its control.

Thus, the aim of this paper is to call for attentions and concerted actions of all stakeholders and concerned bodies by describing the potential damage of the pest, its entry, pathways and establishing control methods. There is also a need for Tanzania Ministry of Agriculture and its stakeholders to meet, discuss and forming multi-stakeholders strategies that will help to control and eliminate completely T. absoluta; and further forming a task force that will implement all agreed resolutions.

\section{The Pest}

Tomato leaf miner Tuta absoluta (Meyrick) (Lepidotera, Gelechiidae) is a serious invasive tomato pest native to South America [2, 7, 10], which has affected the production of tomato worldwide. T. absoluta is a species of moth in family Gelechiidae known by the common names tomato leaf miner, South American tomato moth, tomato borer or South American tomato pinworm [2, 11]. It predominantly found in areas below $1000 \mathrm{~m}$ above sea level. The pest has introduced in Tanzania accidentally through exchange of tomato fresh fruits and planting materials $[3,4]$. The Leaf miners might have introduced to Tanzania likely from border countries like Uganda, Zambia and Kenya, as these were first affected countries prior to Tanzania. Lack of strong quarantine regulations or poor enforcement of available regulations and lack of screening at the boarders are the factors behind the spread of the pest in Tanzania and in other African countries $[12,13]$.

Adult moths have no problem but its Larvae can destroy tomato plants during all growth stages. The pest life cycle start with eggs, larvae, pupa and adult moth. Larvae pass through four growth stages or instars. The larvae feeds upon tomato plants, producing large galleries in leaves, burrowing in stalks, and consuming apical buds and green and ripe fruits and can thus cause up to $100 \%$ loss in tomato production if control measures were not observed. So, leafminers are such a well-known and serious pest of tomato crops in Europe, South America, North America, Asia and some Africa countries [2]. The African countries facing the problem of T. absoluta include Algeria, Egypt, Kenya, Libya, Mozambique, Nigeria, Tunisia, Zambia, Botswana, Ethiopia, Sudan, Niger, Senegal, Uganda and Tanzania [2]. Tuta absoluta is now one of the key pests of tomato in Tanzania that pose a serious agricultural threat to tomato production. Their control using chemical pesticides is extremely difficult and quite challenging. Three reasons can be given to explain why their controls using the chemical method is challenging.

i. Larvae mines within plant tissue (within stem, leaves and fruits) and are thus protected from contacting insecticides[14]. Chemical pesticides works well only when they contact with pest; as they feed within the plant tissues, they are protected from contacting the chemicals, hence reduction in pesticide's field performance.

ii. The large range of its host plants increasing its persistence in the cultivated areas and overwintering potential. Despite the tomato being the primary host for T. absoluta, it has other hosts (cultivated Solanaceae and wild Solanaceae). Cultivated Solanaceae that are host to leafminers are eggplants, peppers, potatoes, beans and tobacco and the wild Solanaceae are Datura species [2]. This will make the pest persistent in cultivated and uncultivated areas for long time.

iii. Their ability to develop resistance towards insecticides is another factor, which makes their control quite challenging. Resistances of the pest to various chemical pesticides have been reported in Brazil, Chile and Argentina. The pests were reported to be resistant to dozens of insecticides including diamide insecticide chlorantraniliprole, abamectin, methamidophos, permethri cartap[15].

iv. They have high reproduction potential, capable of producing 10 to 12 generations per year under the favorable conditions. With such high reproduction potential, they are likely to undergo genetic changes (mutation) which in turn causes resistance to pesticides [16, 17].

What many farmers in Tanzania may not know is that pests like T. absoluta, which have a short generation time and high reproductive potential, are at an increased risk of developing resistance to insecticide use. To avoid a similar predicament, a shift in current pest management practices in Tanzania is necessary. An Integrated Pest Management (IPM) strategy that employs a holistic integrated approach is likely to enhance the control of T. absoluta and other pests. There is a need for the tomatoes stakeholders and agricultural sector in the country to develop a comprehensive strategy to fight the pest. These strategies may help in early detection of the pest and stop the multiplication of the pest before they cause any serious damage.

\subsection{Origin and geographical distribution of T.absoluta}

Over the last decade, its pest status has increased in importance as it has migrated into new territories. The species is thought to originate from Chile and to have spread to South America, Europe then to South East 
Asia and is now moving south from the lower Mediterranean shores into Africa on different solanaceous crops after developing resistance to the commonly used plant protection products[2, 7, 18, 19, 20]. The review by [2] considered the following countries to be infested with T. absoluta: Albania, Algeria, Argentina, Austria, Bahrain, Belgium, Bolivia, Brazil, Bulgaria, Cayman Islands, Chile, Colombia, Cyprus, Czech Republic, Denmark, Ecuador, Egypt, Estonia, Ethiopia, Finland, France, Germany, Greece, Hungary, Iran, Iraq, Ireland, Israel, Italy, Jordan, Kosovo, Kuwait, Latvia, Lebanon, Libya, Lithuania, Luxembourg, Malta, Morocco, Netherlands, Palestinian Authority (West Bank), Panama, Paraguay, Peru, Poland, Portugal (including the Azores), Qatar, Romania, Russia, Saudi Arabia, Senegal, Slovakia, Slovenia, Spain (including the Canary Islands), Sudan, Sweden, Switzerland, Syria, Tunisia, Turkey, United Kingdom (all regions), Uruguay, Venezuela, and Western Sahara.

The rapid distribution of $T$. absolutes over wide geographic areas may be a result of various factors such as its high biotic potential, the large range of its host plants (increasing its persistence in the cultivated areas and overwintering potential), the intra-continental dispersal facilitation due to human transportation and the artificial selection of insecticide-resistant populations[2, 7, 18, 19]. Furthermore, the absence of co-evolved natural enemies may explain why the pest population dynamics in the newly invaded areas are faster than in the native area, where natural enemies are more frequent [21].

\subsection{Entry and pathways of T. absoluta}

The pest was introduced to Tanzania from neighboring countries affected early than Tanzania likely Kenya, Ethiopia, Uganda, Mozambique, and Sudan. Porous East Africa borders and lack of quarantine regulations among other reasons might have facilitated the quick spread to Tanzania. The most relevant pathways for entry of T. absoluta are import of tomato fruits intended for consumption from countries where the pest is present; packing materials boxes, crates, pallets, etc. for import of tomatoes, eggplants, potatoes, tobacco and peppers from countries with pests; the planting material originating from countries where the pest is present (mainly tomatoes) [2, 8, 18].

Seedlings; if tomato plants are being imported from infested areas, probability of pest survival during transportation or storage is high since they are transported or shipped alive with leaves.

Tomato fruits; Fresh tomatoes are considered high risk as the probability of larvae associated with fresh tomatoes surviving transport is high. Fruits in trade should have no signs of insect damage.

Production facilities; several production facilities also repack and /or distribute tomato fruit. There is a high risk in repacked tomato consignments as if pest arrives in late larval stage or as pupa it can develop into a moth at the packing station. Outdoor markets that sell tomatoes from infested countries and if located in areas with suitable summer conditions for survival of T. absoluta, can also pose a risk.

Farm equipment and transportation vehicles- Farm equipment from infested areas that is associated with transportation should be kept clean. Importing countries should ensure that crates that returned to tomato producers from packing operations are sterilized. All packaging with infested fruit should be disposed off properly.

\subsection{Host plants of T. absoluta}

T. absoluta has major host, minor host and wild host. The tomato (L. esculentum) is the main host plant for T.absoluta [21,22]. According to [22], the species attacks other species of cultivated Solanaceae: potatoes (Solanum tuberosum), eggplants (Solanum melongena), pepinodulce (Solanum muricatum), peppers (Capsicumspp.) and wild Solanaceae such as Lycopersicon hirsutum, S. americanum, S.elaeagnifolium, S. hirtum, S. lyratum, S. nigrum, S.puberulum, Physalis angulata, Datura stramonium, D.ferox and Nicotiana glauca, etc[2]. Since becoming established in Europe, T. absoluta has also occasionally been found on several species of plants, such as the sweet pepper (Solanum muricatum), tobacco (Nicotianatabacum L.), bean(Phaseolus vulgaris L.) cape gooseberry (Physalis peruviana L.), green beans (P.vulgaris), Lycium sp. and Malva $s p[8,21]$. In Sub-Saharan Africa, it is possible that T.absoluta attacks not just the cultivated Solanaceae but also local species of the genus Solanum, such as African eggplants (S. aethiopicum, Kumba and Gilo group, S.anguivi, S. americanum, S. macrocarpon, S. scabrumand S. villosum). Besides, the larvae of T. absoluta can also be found on wild hosts such as D. stramonium L., DaturaferoxL., Lycium chilense (Coralillo), L. hirsutum L.,N. glauca (Graham), S. lyratum Thumberg, S. puberulum Nuttal ex Seemann, and S. nigrum L. [2]. Tomato leafminer was also reported feeding on alfalfa, Medicogo sativa, in Iraq[23]. As for [24]; different plant species have been reported as alternative hosts of this insect as Capegooseberry (Physalis peruviana L.), bean (Phaseolus vulgaris L.), Lyciumsp. L. and Malva sp. L. This range indicates that T. absoluta shows a high propensity to use various plants as secondary hosts $[9,25]$. 


\subsection{Behavior of T. absoluta}

Many authors have described T. absoluta (e.g. [2, 8, 21, 22, 25]. According to these authors, $T$. absoluta is a micro lepidopteron moth with high reproduction potential. The pest was reported to produce about 10-12 generations per year under the favourable conditions. A single life cycle is completed within 30-35 days. Adults are nocturnal and hide between leaves during the day time.Their activity is concentrated in the early morning and evening; during the rest of the day, they remain hidden among the leaves. Adults are silvery gray with black spots on the forewings and a wingspan reaching $10 \mathrm{~mm}$. Adult lifespan ranges between 10 and 15 days for females and 6-7 days for males. The female lays the eggs mainly on the leaves, although they can also be found on stems and sepals.The number of eggs per female is usually between 40 and 50 and may reach 260 before completing the life cycle. Eggs are laid isolated, thus facilitating their distribution on the crop. Eggs are small cylindrical, creamy white to yellow $0.35 \mathrm{~mm}$ long. Egg hatching takes place 4- 6 days after egg lying; eggs are hatched into larvae, which develop in to four larval stages called instars. The larvae start feeding on stem, leaves, buds and fruits. Young larvae are cream in colour with dark head. As they develop, the larvae become greener and slightly pink in the last instar. Larval development goes through four stages and pupation may take place in the soil, on the leaves and even within the galleries or other parts of the plant. Larvae enter diapauses in absence of food. T. absoluta can overwinter as eggs, pupae or adults depending on environmental conditions. Larval period that is most damaging completed within 12-15 days; as they seriously feed within plant leaves, buds, stem and fruits.

\section{Management of T. Absoluta}

Different management options exist for the control of T. absoluta. Some of the management options include detection, identification and control methods.

\subsection{Detection and identification}

According to $[2,8,26,31$, and 43$]$, the use of pheromone traps is a reliable method to detect the presence of $T$. absoluta. Pheromone traps have $T$. absolutanatural sexual attractants; so the technique catches adult male moths only. Once caught, the sample is taken to the insects' research centers for identification. Pheromone traps are not only used for detection of the pest, but also for controlling population of T. absoluta through mating disruption and mass annihilation. Pheromone trap data give early warning of the infestation and also will alert the user to low level of populations before they become serious. Different types pheromone trapping techniques are known [8], these include:

Water trap; it consist of a plastic container holding water and a pheromone lure. The lure is secured above the water with a wire attached at both ends of the container.

Sticky rolls; these are rolls with $T$. absoluta pheromone incorporated into the sticky glue, with the pheromone gradually released from the adhesive layer.

Delta traps; these are of two types i.e Cardboard delta triangle with sticky surface and Cardboard delta triangle with a removable liner. Either one is suitable, although delta traps with nondrying sticky liners are preferred. Traps are available from several suppliers in multiple colors and all should be considered equivalent.

\subsubsection{Sex pheromone-based control strategies}

Pheromones are chemicals that are secreted in bodily fluids that are believed to influence the behavior of the opposite sex, such as triggering sexual interest and excitement. Pheromones act as natural sexual attractants. According to[8]; Sex pheromones are chemical signals released by an organism to attract an individual of the same species of the opposite sex. Tuta absoluta pheromone lure has been identified as (3E, $8 \mathrm{Z}$, 11Z)-3,8,11-tetradecatrienyl acetate as major and (3E,8Z)-tetradecadien-1-yl acetate minor component [8].

The review report by [8] described that, majority of female sex pheromones identified in Lepidoptera consist of a mixture of two or more compounds, which not only evoke long-range male attraction but also elicit courtship behavior. The pheromone based control of tomato leafminer, Tuta absoluta is more recommended to be used in combination with other techniques, as it is environmentally safe management method. It is the technique that can be used for pest detection, population monitoring, mass annihilation and mating disruption [8, 31, 43]. It has been successfully applied in controlling leafminers on both greenhouses and open field in many places like South America, Europe, Asia and North Africa. A research study conducted by [45] in Egypt, where sex-pheromone was combined with other pesticides in controlling infestation of tomato by leafminers showed a promising results.

\subsection{Control methods}

T. absoluta is a very challenging pest to control due to its resistance to pesticide, feeding habit and high reproduction capacity, which in turn may lead to gene mutation. The use of chemical pesticides was once uses as a sole control method, but has been declining with time. The pest was reported to developed resistance to 
dozens of pesticides. T. absoluta are well controlled by a combination of practices that are not fully effective when used alone. Various control strategy could applied to control leafminers. To control the pest effectively it is critical to combine all available control measures including physical methods, cultural methods, biological control agents and the correct use of registered pesticides $[2,8,26]$.

\subsubsection{Physical controls}

According to $[2,8,26]$; T.absloluta and other flying pests like bollworm, thrips and whitefly can be physically excluded from tomatoes grown inside the greenhouses using different methods. This may include screening of vents in the roof and sides of greenhouses and the disciplined use of double entry doors can reduce migration of pests into the greenhouse. Outward facing fans inside the double entry porch can blow back any flying insect pests, which might otherwise be 'sucked' into the crop on thermal currents when the outside door opens.

\subsubsection{Screening the greenhouse vents and installation of double-doors}

Greenhouses should be fitted with insect exclusion nets throughout and all doors capable of being sealed tightly. To prevent the entry of the pest, nets with a minimum density of $9 \times 6$ threads $/ \mathrm{cm}^{2}$ have to be used[8]. Any openings or gaps in the structure should be avoided. Human movement from infested to noninfested greenhouses should be avoided and growers should make sure that live adult moths are not present on their person before entering greenhouses [2].This method may be a useful measure to exclude T. absoluta adults. It has to be taken into account that screening the greenhouse will also reduce natural colonization by parasitoids and predators, thus biological control based on the conservation of beneficial insects may be hampered. Nets also reduce greenhouse ventilation, so measures to encourage air movement have to be implemented $[2,8]$.

\subsubsection{Biological control methods}

The development of resistance to synthetic insecticides is one of the driving forces for changes in insect pest management[27].Many research studies show that integration of chemical, cultural and biological control measures are getting popular as integrated pest management (IPM), components, throughout the world[2, 9]. In this regard, biological control occupies a central position in Integrated Pest Management (IPM) Programmes. This is because biological control agents for pests and weeds have enormous and unique advantages; it is safe, permanent, and economical. Biological control method is potentially very beneficial tactic to develop [23, 28].It has been used against crop pest insects belonging to the orders Homoptera, Diptera, Hymenoptera, Coleoptera and Lepidoptera, among others. According to [21, 14, 29, 30]; biological control agents (living antagonistsnatural enemies: predators, parasitoids and pathogens) are considered as one possible solution of the T. absoluta crisis. This strategy offers a more sustainable and less expensive alternative to chemical use.

\subsubsection{Predators}

The natural enemies for T. absoluta have been reported from their place of origin (South America). These enemies of T. absoluta are commercially available and can be used in its control. A paper by [2,31, 32] highlighted list of commercially available predators that have been useful. These may include Predatory bugs such as Macrolophuspygmaeus(commercially available as Macrolophuscaliginosus) and Nesidiocoristenuis have been identified as the most promising natural enemies of T. absoluta in Europe as they are large consumers of eggs of the pest. In the Mediterranean production areas, these two species naturally colonize tomato crops not sprayed with broad-spectrum insecticides and they are released for biological control in greenhouse tomato crops. Other identified predators of T.absoluta are the mirid Dicyphusmaroccanus, the nabidNabispseudoferusibericusand the two phytoseid species Amblyseiusswirskiiand Amblyseiuscucumeris(these two mites in aubergine (eggplant)[2, 31]. Another done by [32] in Mediterranean region using Nesidiocoristenuis, showed highly promising results and effectiveness of predator use when combined with other methods in controlling T. absoluta.

\subsubsection{Parasitoids}

These are one of natural enemies that can be used to control population growth of t. absoluta in both greenhouses and open field tomato farms. They are the most widely used natural enemies of T. absoluta in South America, where the pest originated. In Europe, parasitoids have been found parasitizing T.absoluta larvae in the Mediterranean area[33]. At least two species of Necremnus have been identified in Spain and Italy. Stenomesius spp. and other undetermined species (mainly Braconidae) occur spontaneously in infested tomato plots in Spain, indicating that native parasitoids are adapting to the new host. Regarding parasitoids of T.absoluta eggs, Trichogrammaacheae has been identified as a potential biological control agent of the pest and is currently being released in commercial tomato greenhouses $[2,8]$. 


\subsubsection{Entomopathogens}

Research by [9, 27, 34] revealed poor documentation on effectiveness of entomopathogens controlling T. absoluta with the exception of Bacillus thuringiensis var. kurstaki. Bacillus thuringiensis, an entomopathogenic bacterium has been used in the control of tomato plant pests and reported by many authors as very effective bio-insecticide [34]. It has been used extensively to control the pest in crops where IPM programmes based on biological control are applied. Bio-insecticides like Bacillus thuringiensis do not raise any environmental concern as they are environmentally friendly. In addition, the entomopathogenic nematodes Steinernema carpocapsae, Steinernemafeltiae and Heterorhabditisbacteriophora have proved to be capable of infecting late larval instars of T. absolutaand hence be used in its control [9, 27]

\subsubsection{Cultural control methods \\ 3.2.3.1 Good agricultural practices}

Good agricultural practices for the control of Tuta absoluta include crop rotation with non-solanaceous crops (preferably Cruciferous crops), ploughing, adequate irrigation and fertilization, removal of infested plants and complete removal of post-harvest plant debris and fruit[2]. The removal of wild solanaceous host plants near the growing area is also encouraged, as these can host all stages of the pest, which can then re-infect the growing crop. Through good agricultural practices; cultural practices, rotation with non-solanaceous crops, ploughing, adequate fertilization, and irrigation, destruction of infested plants and post- harvest plant debris, $T$. absoluta can be controlled. For instance, at any time of the growing cycle is detected or fruit stalks damaged by larvae of T. absoluta, there will be an overhaul of the whole plot, the process of withdrawal and destroyed securely to prevent the pest completes its cycle and continue to spread. There are a number of cultural control measures that aid the eradication of this pest. Crop rotation, crop removal and the selective removal and destruction of infested plant material are important cultural control practices that would help eradication of this pest in green houses. The wild host plants should also be removed to prevent the further build up of a potential population [2].

\subsubsection{Management of plant material}

According to [2], the use of transplants free of pests may be useful in control of T. absoluta. When the pest damage is low, it is important to remove any of symptomatic leaves, stems and fruits affected by the presence of larvae or pupae and place them in plastic bags to destroy. Remove weeds that may be host to the pest within the area of vicinity. To prevent population build up one should not leave infested plant material (from pruning or weeding) on the ground, as the larvae will quickly leave them and colonize new plants. After harvesting, crop residues should be destroyed as soon as possible.

\subsubsection{After harvest destruction of crop residues}

The crop residue after the harvest of tomato, potatoes, eggplants or peppers should be destroyed as soon as possible. They can be destroyed by either burning, buried or covered with transparent plastic film to ferment them. Soil solarisation may be useful in warm climates to kill pupae that remain in the soil. Leave a minimum of six weeks between successive susceptible crops.

\subsubsection{IPM Strategies}

Some insects may be controlled by a combination of practices that are not fully effective when used alone. T. absoluta is one of those insects that require more than one practice to be controlled successfully. Therefore, integrated pest management (IPM) programs are being developed in several countries to manage infestations of T. absoluta [9]. To control the pest effectively it is critical to combine all available control measures including cultural methods, biological control agents and the correct use of registered pesticides. IPM strategies are being developed in South America to control T. absoluta. Various active substances can be applied in combination with bio rational control tactics [2]. The integrated control method recommended employs, massive trapping before planting, clearing the soil of crop residues, the application of imidacloprid in the irrigation water 8- 10 days after planting, the application of either spinosad or Indoxacarb if occasional individuals of T.absoluta are observed and elimination of the remnants of the crop immediately after the last fruits have been harvested. The integration of chemical and biological control is often critical to the success of an integrated pest management (IPM) program for arthropod pests. An integrated pest management strategy (indicated below) can be used for the control of Tuta absoluta: (1) Clearing the soil and area of crop residues, fruits and wild host plants, (2) Mass trapping begin prior to planting or upon planting, (3) The use of sulphur, neem oil, Bacillus thuringensis in conjunction with the application of either $\delta$-methrine, spinosad, Indoxacarb or other recommendable bio-pesticide if occasional individuals of Tuta absoluta are observed, (4)Eliminationand burningof infected plants during the growing season and of the remnants of the crop immediately after the last fruits have been harvested. 


\subsubsection{Chemical control methods}

Chemical control using synthetic insecticides is the primary method to manage the pest, but it has serious drawbacks, including reduced profits from high insecticide costs, destruction of natural enemy populations, build up of insecticide residues on tomato fruits and in the environment and fundamentally the rapid development of insecticide resistance. Besides, the efficiency of chemical control of tomato leaf miner infestations has been poor because of (1) the entophytic habit of its larvae, which are protected in the leaf mesophyll or inside fruits $[8,36]$ and (2) pest resistance against a number of applied insecticides $[6,7,19]$. In order to reduce the excessive use of insecticides in tomato fields, environmentally sound control strategies have been developed, including cultural control measures (e.g. crop rotation, selective removal and destruction of infested plant material), the use of natural enemies (parasitoids, predators, entomo pathogens and nematodes) [21, 37].Additional alternative control methods, based on the use of the insect's sex pheromones, have also been developed to control T. absoluta.

\subsubsection{Pesticides}

The list of pesticides is available in the market to control Tuta absoluta but most of these pesticides have demonstrated field failure as the pest have develop resistance to dozens of applied pesticides [8]. Chemical control is difficult because the larvae feed inside leaves, fruits and stems. In addition, pests such as T. absoluta, with a high reproductive capacity and very short generations, have an increased risk of developing resistance[38]. It is therefore crucial to avoid systematic applications, and only apply treatments according to pest population density and crop damage following the recommendations of advisers. It is also essential to alternate the use of active substances with different modes of action (chemical group). Resistance was also reported on $\delta$-methrin, abamectin, methamidophos [7]. One study conducted in Brazil in 2014 by Campos M.R, revealed Tuta absoluta resistance to spinosad. The research at South-East Sicily (Italy) by [39] confirmed the first case of diamide-resistant to Tuta absoluta. Diamide pesticides include chlorantraniliprole, flubendiamide. Cartap was once used as registered pest for control of leafminers but according to [40] the pesticide demonstrated control failure against leafminers.

To control the pest effectively it is critical to combine all the control measures available and not to rely only on insecticide sprays. It is very important to pay attention to the side effects of pesticides on natural enemies, especially predatory bugs. As these individuals often have a slow establishment process. The insecticide should be selected carefully, especially in the early growth stages of the crop. Pyrethrin, carbaryl and $\delta$-methrin in the South American countries. Others include spinosin, indoxacarb, abamectin, emamectin benzoate and cyromazin. Resistance to abamectin, cartap, methamidophos and permethrin has been reported from Brazil $[20,40]$. Resistance to abamectin, $\delta$-methrin and methamidophos was also detected in Argentina [7], and resistance to organophosphates and pyrethroid insecticides has been reported in Chile. A recent study on resistance to 10 different insecticides in Brazilian populations of T. absoluta found that resistance prevails for insecticides commonly employed in open fields, and that weather conditions and spatial dependence play an important role in favouring resistance to some insecticides [20, 19, 42].

\subsection{Potential risks associated with introduction of the pest to Tanzania}

Tuta absoluta has posed many challenges in many country were they are introduced. If the present pest status will not be put under control, some potential risks are expected. The potential risks associated with the introduction of T. absoluta may include;

- Export restrictions might be applied against Tanzania due to T.absoluta outbreaks. Quarantine regulations will require application of import restriction from the countries affected by T. absoluta. This in turn will affect the export and hence weakening of economy.

- Serous losses will encourage farmers to switch to other crops leading to output reduction; as well the serious loss will also create burden to farmers and their families as most of farmers in Tanzania invested in tomato production using loans from banks and other financial institutions.

- The risk of over use of insecticides application leads to increase in health risk to consumers as well as negative environmental impact.

\section{Conclusion And Recommendation}

Tomato is one of the most important edible and nutritious vegetable crops in Tanzania that is grown on both greenhouses and open field. The average yield of tomato in Tanzania has been decreasing in recent years due to several factors including pest and diseases. The most important insect pest that is of economic importance to tomato production is the new devastating pest, tomato leaf miner -Tuta absoluta (Meyrick). The pest attacks the aerial part of the plant (stem, leaves, and fruit) in all stages of tomato growth; thus capable of causing production loss of up to 80 to $100 \%$. Over the last decade, its pest status has increased world- wide as it has migrated into new territories. 
The rapid distribution of T. absoluta over wide geographic areas may be a result of various factors such as its high reproduction potential, large range of host plants (increasing its persistence in the cultivated areas and overwintering potential) and the intra-continental dispersal facilitation due to human transportation. The absence of co-evolved natural enemies may explain why the pest population growth in the newly invaded areas are faster than in the native area, where natural enemies are more frequent. However, there is no silver bullet for $T$. absoluta control, different management options exist for the control of T. absoluta. Some of the management options include detection, identification and control methods. For the effective control, there is a need to establish a T. absoluta monitoring program, establish international, national and regional quarantine regulations. In areas that have not yet been invaded by the pest, it is essential to monitor ports of entry and borders adjoining infested countries with pheromone traps, inform the public about the impending danger of $T$. absoluta invasion via mass media, establish quarantine regulations to prevent the introduction of $T$. absoluta ands end suspected specimens collected in the pheromone traps for identification. Many researchers have reported T. absoluta resistance to many pesticides and still developing resistance over time. In this regard, there is no any single satisfactory method for Tuta absoluta control. However; to control the pest effectively, it is critical to combine all available control measures including physical, cultural and biological methods and the correct use of registered pesticides. The IPM that employs the holistic approach is a best alternative we have at hand.

The way forward for control of Tuta absoluta in Tanzania should include the following measures:

- The ministry of agriculture with help of other stakeholders should form a task force that will implement the strategies to control and eliminate leafminers completely.

- The task force should quantify the affected tomato farmers: Affected farmers should report through agricultural sectors to enable the ministry to set the action plan.

- Educate administrators, scientists, and the public about the impending danger of Tuta absoluta invasion. This will include conducting awareness campaigns involving tomato farmers.

- Creating an efficient Integrated Pest Management (IPM) strategy that suit Tanzania context and should include capacity building programmes on IPM.

- Push for mass trapping of the pest using sex pheromone traps starting with most affected areas should be given high priority. This will call for increased importation of traps by the government. The government through ministry of agriculture needs to subsidize the cost of traps.

- Excessive use of pesticides pose environmental challenges, so there is a need of encourage bio-friendly pesticides as means of controlling and preventing leafminers.

- Coming up with a list of chemicals that are available in Tanzania, that will be used for prevention and controlling of the pest

- Adopt both boarder and in-country quarantine measures to prevent its introduction. These would include such steps as not allowing the import of tomatoes with stems, leaves, or a calyx (the green sepals of a flower that form an outer floral envelope). Nature of East African borders requires harmonization of quarantine regulations.

\section{Acknowledgements}

We highly acknowledge Maneno Chidege for his assistance in accessing Pheromone traps during the field work and for giving information on presence on T. absoluta in area of our target, Tanzania rift valley area especially MtowaMbu. Our heart- felt thanks should go to Mzee Andrea Laizer for keeping; managing and providing the land were we established our experimental plots. He also helped to arranged for Farmers outreach, where we carry out some interrogations with farmers to assess their understanding on T. absoluta.

\section{References}

[1] Bawin T, De Backer L, Dujeu D, et al. Infestation level influences oviposition site selection in the tomato leafminer Tuta absoluta (Lepidoptera: Gelechiidae). Insects. 2014;5(4):877-884.

[2] Retta AN, Berhe DH. Tomato leaf miner - Tuta absoluta (Meyrick), a devastating pest of tomatoes in the highlands of Northern Ethiopia : A call for attention and action. Res J Agric Environ Manag. 2015;4(6):264-269.

[3] Materu CL, Shao EA, Losujaki E, Chidege M. Farmer's Perception Knowledge and Practices on Management of Tuta Absoluta Meyerick ( Lepidotera Gelechiidae ) in Tomato Growing Areas in Tanzania. 2016;3(2):1-5.

[4] Chidege M, Al S, Hassan N, Julie A, Kaaya E, Mrogoro S. First record of tomato leaf miner Tuta absoluta ( Meyrick ) ( Lepidoptera : Gelechiidae ) in Tanzania. Agric Food Secur. 2016:1-7.

[5] Assaf LH, Hassan FR, Ismael HR, Saeed S a. Population Density of Tomato leaf miner Tuta absoluta Meyrick ( Lepidoptera : Gelechiidae ) under plastic houses conditions ( b ). IOSR J Agric Vet Sci. 2013;5(4):7-10.

[6] Fe S, Aires B, Aires B. Insecticide Resistance in Argentine Populations of Tuta absoluta ( Meyrick ) ( Lepidoptera : Gelechiidae ). 2005;34(February):113-119.

[7] Arn J. Prospects for the biological control of Tuta absoluta in tomatoes of the Mediterranean ' b and Rosa Gabarra b. 2012;(June 2011).

[8] Megido RC, Haubruge E, Verheggen FJ. Pheromone-based management strategies to control the tomato leafminer, Tuta absoluta ( Lepidoptera : Gelechiidae ). A review. 2013;17(3):475-482.

[9] Gözel Ç, Kasap I. Efficacy of entomopathogenic nematodes against the Tomato leafminer, Tuta absoluta (Meyrick) (Lepidoptera: 
Gelechiidae) in tomato field. Turkiye Entomoloji Derg. 2015;39(3):229-237.

[10] Balzan M V., Moonen AC. Management strategies for the control of Tuta absoluta (Lepidoptera: Gelechiidae) damage in open-field cultivations of processing tomato in Tuscany (Italy). EPPO Bull. 2012;42(2):217-225.

[11] Satti A. Alien insect species affecting agriculture and natural resources in Sudan. Agric Biol J North Am. 2011;2(8):1208-1221.

[12] Mwatawala MW. Tuta absoluta yet another invader at the Tanzanian doorstep. Intercont Hotel Addis Ababa, Ethiop Novemb 2628th, 2013. 2013.

[13] Cherif A, Mansour R, Grissa-lebdi K. Biological aspects of tomato leafminer Tuta absoluta ( Lepidoptera: Gelechiidae ) in conditions of Northeastern Tunisia : possible implications for pest management. Environ Exp Biol. 2013;11:179-184.

[14] Sevcan O ztemiz. Population of Tuta absoluta and natural enemies after releasing on tomato grown greenhouse in Turkey. African J Biotechnol. 2013;12(15):1882-1887.

[15] Haddi K, Berger M, Bielza P, et al. Identi fi cation of mutations associated with pyrethroid resistance in the voltage-gated sodium channel of the tomato leaf miner ( Tuta absoluta ). Insect Biochem Mol Biol. 2012;42(7):506-513.

[16] Arnó J, Gabarra R. Controlling Tuta absoluta, a new invasive pest in Europe. Endur Train Integr Pest Manag - Number 5. 2010;(5):8. www.endure-network.eu.

[17] Muruvanda DA, Holden D, Juarez M, Ramos C, Figueroa T, Lee R. Surveillance Protocol for the Tomato Leaf Miner , Tuta absoluta $\quad$ for NAPPO Member Countries. http://www.aphis.usda.gov/import_export/plants/plant_exports/downloads/Tuta_absoluta_surveillanceprotocol_08-06-2012-e.pdf.

[18] Gontijo PC, Picanc MC. Spatial and temporal variation in the control failure likelihood of the tomato leaf miner, Tuta absoluta. 2013;162:50-59.

[19] Silva WM, Silva JE, Siqueira HAA. Spinosyn resistance in the tomato borer Tuta absoluta ( Meyrick ) ( Lepidoptera : Gelechiidae ). 2014.

[20] Siqueira ÂA, Guedes RNC, Picanc MC. Insecticide resistance in populations of Tuta absoluta (Lepidoptera : Gelechiidae ). 2000.

[21] Desneux N, Wajnberg E, Wyckhuys KAG, et al. Biological invasion of European tomato crops by Tuta absoluta: Ecology, geographic expansion and prospects for biological control. J Pest Sci (2004). 2010;83(3):197-215.

[22] Toševski I, Jović J, Mitrović M, Cvrković T. A New Pest of Tomato in Serbia. 2011;26(3):197-204.

[23] Gebremariam G. Tuta Absoluta : A Global Looming Challenge in Tomato Production, Review Paper. 2015;5(14):57-63.

[24] EPPO Reporting Service. 2009:1-16.

[25] Harizanova V, Stoeva A, Mohamedova M. T omato leaf miner, T uta absoluta ( P ovolny ) ( L epidoptera : gelechiidae ) - first record in B ulgaria. 2009;1:95-98.

[26] Ghoneim K. Parasitic Insects and Mites as Potential Biocontrol Agents for a Devastive Pest of Tomato , Tuta absoluta Meyrick ( lepidoptera : gelechiidae ) in the world : A Review. 2014;19(April):36-68.

[27] Mahmoud MF. Biology and Use of Entomopathogenic Nematodes in Insect Pests Biocontrol, A Generic View. 2017;(1923).

[28] Luna MG, Sánchez NE, Pereyra PC, et al. Biological control of Tuta absoluta in Argentina and Italy: Evaluation of indigenous insects as natural enemies. EPPO Bull. 2012;42(2):260-267.

[29] Zappalà L, Biondi A, Alma A, et al. Natural enemies of the South American moth, Tuta absoluta, in Europe, North Africa and Middle East, and their potential use in pest control strategies. J Pest Sci (2004). 2013;86(4):635-647.

[30] Bale JS, van Lenteren JC, Bigler F. Biological control and sustainable food production. Philos Trans Biol Sci. 2008;363(1492):761776.

[31] Refki E, Sadok BM, Ali BB. Study of the biotic potential of indigenous predator Nesidiocoris tenuis on Tuta absoluta pest of geothermal culture in the south of Tunisia. 2016;4(6):692-695.

[32] Sanchez JA, La-spina M, Lacasa A. Numerical response of Nesidiocoris tenuis ( Hemiptera : Miridae ) preying on Tuta absoluta ( Lepidoptera : Gelechiidae ) in tomato crops. 2014;111(3):387-395.

[33] Al-jboory IJ, Katbeh-bader A, Shakir A, Ipm R, Avenue T, Park DI. First Observation and Identification of Some Natural Enemies Collected from Heavily Infested Tomato by Tuta absoluta ( Meyrick ) ( Lepidoptera : Gelechiidae ) in Jordan. 2012;11(6):787-790.

[34] Youssef NA, Hassan GM. Bioinsecticide activity of Bacillus thuringiensis isolates on tomato borer, Tuta absoluta ( Meyrick ) and their molecular identification. 2013;12(23):3699-3709.

[35] Deanery G, Faculty HE, Sciences B. Characterization and Bioassay of Different Commercial Products of B . thuringiensis Against Four Larval Stages and Adults of an Insect Tuta absoluta in Laboratory Prepared by Raed Maged Mushtaha Supervisor Dr . Tarek El Bashiti.

[36] Cocco A, Serra G, Lentini A, Delrio G. Spatial distribution and sequential sampling plans for Tuta absoluta ( Lepidoptera : Gelechiidae ) in greenhouse tomato crops. 2014;(December).

[37] Gonza J, Urbaneja A. The combined use of Bacillus thuringiensis and Nesidiocoris tenuis against the tomato borer Tuta absoluta. 2011:883-891.

[38] Konus M. Analysing resistance of different Tuta absoluta (Meyrick) (Lepidoptera: Gelechiidae) strains to abamectin insecticide. Turkish J Biochem. 2014;39(3):291-297.

[39] Bassi A, Roditakis E, Flier WG. Alternation of the insecticidal modes of action as a key ipm practice for sustainable control .

[40] Siqueira HAA, Guedes RNC, Picanc MC. Cartap resistance and synergism in populations of tuta absoluta ( lep ., gelechiidae ). 2000; 124: 233-238.

[41] Crespo LB, Silva GA, Picanc MC, Bacci L. Control failure likelihood and spatial dependence of insecticide resistance in the tomato pinworm , Tuta absoluta Jander F Rosado a and Raul Narciso C Guedes a *. 2011;(December 2010):913-920.

[42] Balzan M V, Moonen A. Management strategies for the control of Tuta absoluta ( Lepidoptera : Gelechiidae ) damage in open-field cultivations of processing tomato in Tuscany ( Italy ). 2012;42:217-225.

[43] Abbes K, Chermiti B, Entomologie L, et al. Comparison of two Marks of Sex Pheromone Dispensers Commercialized in Tunisia for their Efficiency to Monitor and to Control by Mass-Trapping Tuta absoluta under Greenhouses. 2011;6(2).

[44] Refki E, Sadok BM, Ali BB, Faouzi A, Jean VF, Rudy CM. Effectiveness of pheromone traps against Tuta absoluta. 2016;4(6):841844 .

[45] El-aassar MR, Soliman MHA, Elaal AAA. Efficiency of sex pheromone traps and some bio and chemical insecticides against tomato borer larvae, Tuta absoluta ( Meyrick ) and estimate the damages of leaves and fruit tomato plant. Ann Agric Sci. 2015;60(1):153-156. 